\title{
Intracoronary imaging
}

Coronary angiography may have started as an accident when a cardiologist accidentally injected contrast into the small vessels of a patient's heart but in 2020, it remains the gold standard for the assessment of coronary anatomy. Since the first balloon angioplasty in 1977 followed by the first implantation of coronary stent in 1986, coronary angiography has also remained the technique to guide the management of ischaemic heart disease. Over the years coronary angiography has made minimal progress and remains a simple 2-dimensional visual assessment of the vessel lumen which doesn't allow visualisation of vessel wall and plaque characteristics. The birth of intracoronary imaging in the form of intravascular ultrasound (IVUS) which delivers cross-sectional imaging of the coronary vessel in the 1990s, provided a complementary technique to coronary angiography which allows cardiologist to look beyond just the lumen and into plaque. The evolution of intracoronary imaging continued in 2008 when optical coherence tomography (OCT) was used in human in vivo intracoronary imaging studies. Whilst IVUS uses ultrasound waves, OCT uses near-infrared light to construct the cross-sectional image of the vessel. The higher axial resolution of OCT $10-20 \mu \mathrm{m}(40-150 \mu \mathrm{m}$ in IVUS) is offset by the reduced penetration of $1.0-2.5 \mathrm{~mm}$ (4-8 $\mathrm{mm}$ in IVUS). More recently, the development of near infrared spectroscopy (NIRS) has allowed the detection of lipid rich plaque. It is now in clinical use as a multimodality catheter in combination with IVUS and has been shown to positively identify vulnerable patients and plaque (1).

The incorporation of intracoronary imaging to percutaneous coronary intervention (PCI) provides incremental information to guide stent implantation. There is growing evidence that intracoronary imaging does not only enhance the acute procedural result but also improves clinical outcomes (2). Despite this, the uptake of intracoronary imaging in routine clinical practice remains low. This could be related to factors such as (I) cost of intracoronary imaging catheters; (II) additional time required for imaging; (III) inadequate knowledge on how to acquire images, interpret and integrate findings to optimize PCI in routine clinical practice. Cardiologists are often overwhelmed by the lack of universal algorithm on how to optimise stent implantation using intracoronary imaging as different criteria are often chosen in trials. In addition, cardiologists also often feel that the different intracoronary imaging techniques are competing rather than complimentary.

This special series on intracoronary imaging has been arranged to provide our readers an overview of all aspects of intracoronary imaging. The basics, fundamentals and evidence on IVUS, OCT and NIRS are covered in detail in this series. This is followed by a summary of how IVUS and OCT can be incorporated into clinical practice as well as translational research. The aim of this series is to equip our readers with knowledge and confidence on how to incorporate intracoronary imaging into routine clinical practice and ultimately improve patient outcome.

\section{Acknowledgments}

Funding: None.

\section{Footnote}

Provenance and Peer Review: This article was commissioned by the editorial office, Cardiovascular Diagnosis and Therapy for the series "Intracoronary Imaging". The article did not undergo external peer review.

Conflicts of Interests: The author has completed the ICMJE uniform disclosure form (available at http://dx.doi.org/10.21037/ cdt-2019-ici-11). The series "Intracoronary Imaging" was commissioned by the editorial office without any funding or sponsorship. Dr. Wong served as the unpaid Guest Editor of the series, and serves as an unpaid editorial board member of Cardiovascular Diagnosis and Therapy from Feb 2019 to Jan 2021. The author has no other conflicts of interest to declare.

Ethical Statement: The author is accountable for all aspects of the work in ensuring that questions related to the accuracy or integrity of any part of the work are appropriately investigated and resolved. 
Open Access Statement: This is an Open Access article distributed in accordance with the Creative Commons AttributionNonCommercial-NoDerivs 4.0 International License (CC BY-NC-ND 4.0), which permits the non-commercial replication and distribution of the article with the strict proviso that no changes or edits are made and the original work is properly cited (including links to both the formal publication through the relevant DOI and the license). See: https://creativecommons.org/ licenses/by-nc-nd/4.0/.

\section{References}

1. Waksman R, Di Mario C, Torguson R, et al. Identification of patients and plaques vulnerable to future coronary events with near-infrared spectroscopy intravascular ultrasound imaging: a prospective, cohort study. Lancet 2019;394:1629-37.

2. Elgendy IY, Mahmoud AN, Elgendy AY, et al. Outcomes With Intravascular Ultrasound-Guided Stent Implantation: A MetaAnalysis of Randomized Trials in the Era of Drug-Eluting Stents. Circ Cardiovasc Interv 2016;9:e003700.

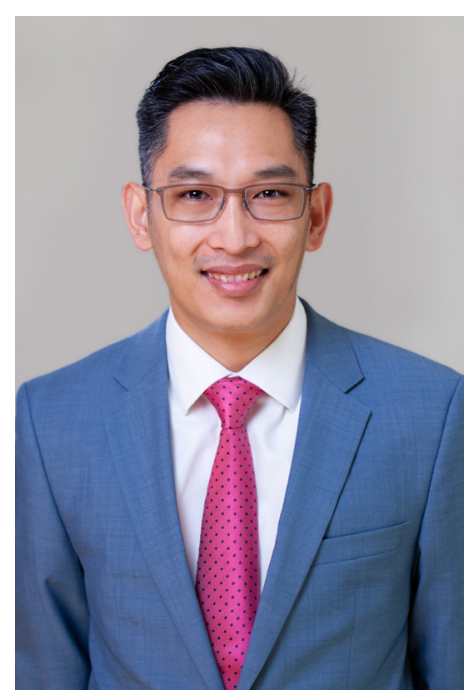

Dennis T. L. Wong

Dennis T. L. Wong, BSc (Med), MBBS (Hons), MD, PhD Monash Cardiovascular Research Centre, Department of Medicine (Monash Medical Centre), Monash University and Monash Heart, Monash Health, Clayton, Australia.

(Email: drdenniswong@yahoo.com.au)

Submitted Aug 10, 2020. Accepted for publication Aug 30, 2020. doi: $10.21037 /$ cdt-2019-ici-11

View this article at: http://dx.doi.org/10.21037/cdt-2019-ici-11

Cite this article as: Wong DTL. Intracoronary imaging. Cardiovasc Diagn Ther 2020;10(5):1356-1357. doi: 10.21037/cdt2019-ici-11 